\title{
Effect of admixture on the pore structure refinement and enhanced performance of alkali-activated fly ash-slag concrete
}

\author{
Citation for published version (APA): \\ Keulen, A., Yu, Q., Zhang, S., \& Grünewald, S. (2018). Effect of admixture on the pore structure refinement and \\ enhanced performance of alkali-activated fly ash-slag concrete. Construction and Building Materials, 162, 27-36. \\ https://doi.org/10.1016/j.conbuildmat.2017.11.136
}

\section{Document license: \\ TAVERNE}

DOI:

10.1016/j.conbuildmat.2017.11.136

Document status and date:

Published: 20/02/2018

\section{Document Version:}

Publisher's PDF, also known as Version of Record (includes final page, issue and volume numbers)

\section{Please check the document version of this publication:}

- A submitted manuscript is the version of the article upon submission and before peer-review. There can be important differences between the submitted version and the official published version of record. People interested in the research are advised to contact the author for the final version of the publication, or visit the DOI to the publisher's website.

- The final author version and the galley proof are versions of the publication after peer review.

- The final published version features the final layout of the paper including the volume, issue and page numbers.

Link to publication

\footnotetext{
General rights

- You may freely distribute the URL identifying the publication in the public portal. follow below link for the End User Agreement:

www.tue.nl/taverne

\section{Take down policy}

If you believe that this document breaches copyright please contact us at:

openaccess@tue.nl

providing details and we will investigate your claim.
}

Copyright and moral rights for the publications made accessible in the public portal are retained by the authors and/or other copyright owners and it is a condition of accessing publications that users recognise and abide by the legal requirements associated with these rights.

- Users may download and print one copy of any publication from the public portal for the purpose of private study or research.

- You may not further distribute the material or use it for any profit-making activity or commercial gain

If the publication is distributed under the terms of Article $25 \mathrm{fa}$ of the Dutch Copyright Act, indicated by the "Taverne" license above, please 


\title{
Effect of admixture on the pore structure refinement and enhanced performance of alkali-activated fly ash-slag concrete
}

\author{
A. Keulen ${ }^{\text {a,b,*, }}$ Q.L. Yu ${ }^{\mathrm{a}, *}$, S. Zhang ${ }^{\mathrm{c}}$, S. Grünewald ${ }^{\mathrm{c}, \mathrm{d}}$ \\ a Eindhoven University of Technology, Department of the Built Environment, P.O. Box 513, 5600 MB Eindhoven, The Netherlands \\ ${ }^{\mathrm{b}}$ Van Gansewinkel Minerals, Eindhoven, The Netherlands \\ c Delft University of Technology, Faculty of Civil Engineering and Geosciences, Delft, The Netherlands \\ ${ }^{\mathrm{d}}$ CRH Sustainable Concrete Centre, Oosterhout, The Netherlands
}

\section{H I G H L I G H T S}

- Relation between workability and setting adjustment and admixture dosage is derived.

- Compressive strength is significantly enhanced by the plasticizing admixture.

- Microstructure refinement by the plasticizing admixture is observed by SEM analysis.

- Pore structure and porosity are investigated by mercury intrusion porosimetry.

- Chloride migration resistance is affected by the admixture at different ages.

\section{A R T I C L E I N F O}

Article history:

Received 18 May 2017

Received in revised form 24 November 2017

Accepted 26 November 2017

\section{Keywords:}

Alkali activated fly ash-slag concrete

Admixture

Workability

Microstructure

Compressive strength

Chloride migration

Pore structure

\begin{abstract}
A B S T R A C T
This paper investigates the influence of a plasticizing admixture on the pore structure refinement of alkali-activated concrete and paste mixtures and the consequently enhanced performance. Alkaliactivated fly ash-slag concrete and paste are designed using a polycarboxylate-based admixture with different dosages. The pore structure and porosity are analyzed using mercury intrusion porosimetry (MIP). The workability, compressive strength, chloride migration resistance and electrical resistivity of alkaliactivated fly ash-slag concrete and paste are determined. The results show that significantly improved workability and strength development are obtained at an increased admixture content. The admixture improves the gel polymerization product layer most likely around the GGBS particles, densifying the matrix. The 28-day Cl-migration coefficient of admixture $\left(1-2 \mathrm{~kg} / \mathrm{m}^{3}\right)$ modified concrete is equal to the reference mixture, while at the highest admixture content the $\mathrm{Cl}$-ingress is increased. At the later ages (91-days), the Cl-migration coefficients of all concretes, non- and admixture-containing samples, are comparable and low (about $2.6 \times 10^{-12} \mathrm{~m}^{2} / \mathrm{s}$ ). The MIP analyses show a significant decrease of the total and effective capillary porosity over time at an increased admixture content. The relationships between the porosity and other properties are discussed, at varying admixture contents.
\end{abstract}

(c) 2017 Elsevier Ltd. All rights reserved.

\section{Introduction}

Alkali-activated slag-fly ash based binders in comparison with traditional Portland cement possess comparable to moderately modified material properties (i.e. mechanical strength, chloride ingress, acid and carbonation resistance) [1-4]. Designing alkaliactivated materials (AAM) with high durability performance lar-

* Corresponding authors at: Eindhoven University of Technology, Department of the Built Environment, P.O. Box 513, 5600 MB Eindhoven, The Netherlands (A. Keulen).

E-mail addresses: arno.keulen@vangansewinkel.com (A. Keulen), q.yu@bwk.tue. nl (Q.L. Yu). gely depends on the mixture composition (design). This is mainly controlled by the applied precursor minerals such as ground granulated blast furnace slag (GGBS) and pulverized coal fly ash (PCFA), and the concentration, type and combination of alkaline activators (i.e. sodium or potassium silicate or hydroxide). More specifically, a higher GGBS content (0-100 wt\%) as a replacement of the PCFA in the binder, favors the matrix densification and strength development [5-8]. By forming mainly calcium dominated gel-structures (C-A-S-H), consequently resulting in a reduced chloride migration rate in concrete [9]. However, to support the practical application and further development of AAM as well as that of Portland cement, both materials are strongly dependent on the availability 
of admixtures [10,11]. Due to the existence of multiple molecular varieties, admixtures (known as superplasticizers (SP's)) can perform very differently in optimizing the fresh concrete mixture state, although this is also dependent on the binder type and composition [12].

For fly ash-dominated AAM systems, the mixture workability, setting time and liquid demand can be relatively easily modified by polycarboxylate and naphthalene type admixtures [13-17]. Although often relatively high admixture dosages $(\geq 1-10 \mathrm{wt} \%$ in relation to the binder content) are required in order to gain a high mixture flowability and consistency [15,17-19], compared to that of Portland cement mixtures (mostly $\leq 1 \mathrm{wt} \%$ ). As a consequence, high dosages lead to unwanted negative side effects, such as increased material porosity and loss of mechanical strength $[15,17]$. For GGBS-dominated AAMs, almost all related admixtures often do not sufficiently modify the mixture workability [20]. In some cases, mixture rheology improvement and setting time retardation are observed to a certain extent when using only a hydroxide instead of a silicate- based activator $[15,20]$. Overall, many of these studies indicate that admixtures are able to reduce the liquid to binder ratio or liquid demand of the fresh mixture. Summarizing relevant literature dealing with the effect of mainly Portland cement-based admixtures on AAM systems, the following remarks can be drawn:

- Admixtures shows no improvement to the delay of the mixture setting time and overall mixture workability, which could be associated with their physical and chemical incompatibility or rapid chemical oxidation in the high alkali system $[13,15,20]$.

- Admixtures mainly enhance the AAM mixture workability over a short period of time ( $\leq 10-40 \mathrm{~min})$. An increasing GGBS and silicate activator content strongly reduce the workability, therefore AAM is often prone to a non-predictable, very rapid decline of the workability and fast setting [15,16,18,20-22].

- Naphthalene and polycarboxylate admixtures are the most effective SPs, to enhance the mixture workability of mainly alkali-activated PCFA systems $[13,15,16]$ compared to GGBSbased systems [15,18,22,23].

- Admixtures use frequently causes negative effects on the setting time and mechanical property of AAM [13,15-18,2022,24].

- Admixtures can have either negative or positive effects on the concrete shrinkage $[20,24]$.

Limited experimental studies have been performed on the effect of admixtures on AAM systems as often admixtures are not able to sufficiently modify AAM concrete [20,25]. However, in recent years, more, while still rather limited commercial admixtures, mainly polycarboxylates, are available for AAM. Further knowledge is required in order to improve the physical and chemical understanding of their working mechanisms, as well as that of their predictability with AAM concrete production.

Apart from the rheology-modifying ability [14], another positive effect is that the microstructure development of AAM concrete can be significantly enhanced by a polycarboxylate. Through densification of the interfacial transition zone (ITZ) [26], located between the newly formed AAM gel structure and solid particles (binder and the aggregate minerals), at which the porosity is reduced. This leads to the shift of pore size of hardened AAM towards smaller ranges which improves the material performance by for instance a higher material strength, reduced permeability and enhanced ion diffusion resistance (e.g. chloride). However, the microstructure development (i.e. porosity and permeability) and the chloride migration of AAM concrete under the influence of using admixture have not been studied. Research is needed to understand the potential physical and chemical mechanisms affected by a working admixture in concrete, contributing to the design of durable AAM concretes for construction structures.

In the present study, a comprehensive approach is applied to investigate the effect of admixture on pore structure refinement and enhanced performance of alkali-activated fly ash-slag concrete. The main objectives of this study are:

- Analyze the influence of the admixture content on the fresh mixture state properties, by measuring the setting time and the workability progression over time;

- Study the influence of the admixture content on the hardened material state properties, by analyzing the AAM compressive strength, chloride migration rate and material electrical resistivity over time;

- Determine the effect of admixture content on the AAM pore structure and progression over time and consequent influence on the material durability (chloride migration);

- Investigate the relation between different system parameters and their significance; such as concrete compressive strength and porosity and their effect on the permeability and chloride migration of concrete over time under the influence of the admixture content.

\section{Experimental setup}

\subsection{Materials}

The used mineral binder (MB) is a blend of $73.7 \mathrm{wt} \%$ pulverized coal fly ash (PCFA) class F in accordance with NEN-EN 450-1 with $25 \mathrm{wt} \%$ granulated ground blast furnace slag (GGBS) and $1.3 \mathrm{wt} \%$ technical grade sodium meta-silicate pentahydrate powder (supplied by $\mathrm{PQ}$, The Netherlands). The elemental composition of the $\mathrm{MB}$ is determined by X-ray fluorescence (XRF), as shown in Table 1.

River aggregates (sand $0-4 \mathrm{~mm}$ and gravel $4-16 \mathrm{~mm}$ ) were used to produce the mixtures. A commercial 33\% liquid sodium hydroxide $(\mathrm{NaOH})$ with a molarity $(\mathrm{M})$ of 11.2 was diluted by tap water to obtain the desired (3M NaOH) system alkalinity. A polycarboxylate plasticizing admixture (supplied by SQAPE Technology), hereafter identified as "admixture", was used to enhance the fresh concrete workability. The polycarboxylate is highly soluble in water and the backbone contains poly-functional reactive side chains, e.g. carboxyl, which initiate the metal (mainly calcium) adsorption reactions. Preliminary research shows that a chemical oxidation effect is observed when mixing this admixture with $\mathrm{NaOH}$ solution that helps to improve the workability. The added additional water, $\mathrm{NaOH}$ and the admixture were summed as the total liquid volume (although solids are present). The relevant

Table 1

Elemental composition (\%) of the mineral binder (MB), determined with XRF.

\begin{tabular}{llll}
\hline Oxides & PCFA & GGBS & MB \\
\hline $\mathrm{SiO}_{2}$ & 59.7 & 34.3 & 51.4 \\
$\mathrm{Al}_{2} \mathrm{O}_{3}$ & 24.6 & 9.8 & 17.9 \\
$\mathrm{CaO}$ & 1.5 & 41.8 & 13.9 \\
$\mathrm{Fe}_{2} \mathrm{O}_{3}$ & 6.8 & 0.5 & 6.3 \\
$\mathrm{MgO}$ & 1.3 & 7.7 & 3.8 \\
$\mathrm{~K}_{2} \mathrm{O}$ & 3.0 & 0.6 & 2.2 \\
$\mathrm{Na}_{2} \mathrm{O}$ & 0.6 & $<0.1$ & 1.1 \\
$\mathrm{TiO}_{2}$ & 1.2 & 1.2 & 1.1 \\
$\mathrm{Mn}_{3} \mathrm{O}_{4}$ & 0.0 & 0.3 & 0.2 \\
$\mathrm{BaO}_{\mathrm{P}} \mathrm{O}_{5}$ & 0.1 & 0.1 & 0.1 \\
$\mathrm{SO}_{3}$ & 0.1 & $<0.1$ & 0.4 \\
$\mathrm{Cl}$ & 1.0 & 3.6 & 1.7 \\
$\mathrm{LOI}\left(950^{\circ} \mathrm{C}\right)$ & $<0.1$ & $<0.1$ & $<0.1$ \\
\hline
\end{tabular}

LOI: loss of ignition. 
Table 2

Materials characteristics.

\begin{tabular}{llll}
\hline Material & $\begin{array}{l}\text { Density } \\
\left(\mathrm{kg} / \mathrm{m}^{3}\right)\end{array}$ & $\begin{array}{l}\text { Water Absorption } \\
(\%)\end{array}$ & $\mathrm{d}_{50}(\mu \mathrm{m})$ \\
\hline PCFA & 2312 & & 20 \\
GGBS & 2893 & & 12 \\
Mineral binder (MB) & 2498 & & \\
Sand (0-4 mm) & 2600 & 0.80 & 650 till 900 \\
Gravel (4-16 mm) & 2590 & 1.80 & \\
Meta silicate powder & 900 & & \\
NaOH solution (33\% pure) & 1360 & & \\
Admixture & 1190 & & \\
\hline
\end{tabular}

PSD: particle size distribution.

material properties, including the specific density, water absorption and mean particle size $\left(\mathrm{d}_{50}\right)$, are listed in Table 2 .

\subsection{Binder composition and admixture}

A predefined AAM binder was used in this study, composing of: (1) the blended mineral binder with meta-silicate and (2) a fixed 3 $\mathrm{M} \mathrm{NaOH}$ activator. Preliminary research and the literature [27] verified that this relatively low activator molarity is able to effectively promote an acceptable setting time and sufficient mechanical strength performance of AAM concrete. The low silicate powder addition, as a part of the $\mathrm{MB}$, is applied to increase the material strength at the early ages of 1-7 days, while higher silicate dosages $(>1.3 \mathrm{wt} \%)$ would reduce the mixture workability. Additionally, the plasticizing and liquid reducing effects of the admixture on paste mixtures containing sole PCFA or GGBS were examined by performing water demand experiments [28]. The results showed that a significant decrease of liquid demand up to 25\% for both PCFA and GGBS can be observed. In overall, PCFA shows a lower liquid demand with an overall factor of about 2 of GGBS. Based on the preliminary study, a high PCFA content $(\approx 75 \mathrm{wt} \%)$ was used for the mineral binder composition, concerning both the mixture liquid demand and binder performance.

\subsection{Sample preparation}

\subsubsection{Concrete mixtures}

The concrete mixtures (Table 3 ) were analyzed on workability (slump) and tested on the compressive strength, the chloride migration rate and the material electrical resistivity over time, to evaluate the effect of admixture. The mixtures (140 L per batch) were prepared with a high-speed rotating pan mixer. During the mixture preparation, firstly sand, gravel and the solid precursors were mixed and then the liquid was added. The total mixing time was 5 min: 1 min of dry mixing (sand, gravel with solid precursors) and 4 min of additional mixing (adding the total liquid). Fresh concrete was cast in steel molds $\left(150 \times 150 \times 150 \mathrm{~mm}^{3}\right)$, vibrated on a compaction table and sealed with a plastic foil. After $24 \mathrm{~h}$ of room temperature curing, the specimens were demolded, covered by plastic and stored at room temperature $\left(\approx 20^{\circ} \mathrm{C}\right)$.

\subsubsection{Paste mixtures}

The workability, compressive strength and pore structure of the designed paste mixtures (Table 4) were analyzed. Mercury intrusion porosimetry (MIP) was used to evaluate the effect of using admixture on the pore structure development. The paste mixtures have the same $\mathrm{L} / \mathrm{B}$ ratio $(0.32)$ and $3 \mathrm{M} \mathrm{NaOH}$ alkalinity as the concrete mixtures; the admixture content per $\mathrm{kg}$ binder was identical with that of the tested concrete mixtures A, B, D and F with a corresponding admixture contents of $0 / 1 / 3 / 5 \mathrm{~kg} / \mathrm{m}^{3}$. During the sample preparation, all components were mixed at once with a Hobart mixer for $5 \mathrm{~min}$ at medium speed. The specimens for strength testing were prepared in polystyrene prism molds $(40 \times 40 \times 160 \mathrm{~m}$ $\mathrm{m}^{3}$ ), compacted on a vibration table and sealed with plastic foil. For the porosity experiments, fresh paste was cast in plastic containers $(\approx 300 \mathrm{ml}$ ) and filled to the top and slightly tamped for air release. Sealed containers were placed on a slowly rotating apparatus to avoid particle segregation, and the rotation apparatus was stopped after paste setting after about $4 \mathrm{~h}$. Samples were stored for curing in a climate room $\left(20^{\circ} \mathrm{C}\right.$ and $\left.\geq 95 \% \mathrm{RH}\right)$ until testing.

\subsection{Test methods}

The slump of the fresh concrete was measured in accordance with NEN-EN 12350-2. During the test period, fresh concrete was mixed at a very low rotation speed (imitation of real-life concrete truck transport mixer process). The flowability of the paste mixtures was determined using a Hägermann cone $(100 \mathrm{~mm}$ base diameter, $70 \mathrm{~mm}$ top diameter and height $60 \mathrm{~mm}$ ), in accordance with EN 459-2.

The compressive strength of concrete was measured at the ages of $1,7,28$ and 56 days respectively in accordance with NEN-EN 12390-3 and the strength of paste samples were performed in accordance with NEN-EN 196-1.

Table 3

Mixture composition of AAM concretes.

\begin{tabular}{|c|c|c|c|c|c|c|c|}
\hline Mixture code & Sand (wt.\%) & Gravel (wt.\%) & Binder $\left(\mathrm{kg} / \mathrm{m}^{3}\right)$ & Total liquid $\left(1 / \mathrm{m}^{3}\right)$ & L/B ratio & $\mathrm{NaOH}(\mathrm{M})$ & Admixture $\left(\mathrm{kg} / \mathrm{m}^{3}\right)$ \\
\hline A & 47 & 53 & 400 & 127 & 0.32 & 3 & 0.0 \\
\hline B & 47 & 53 & 400 & 127 & 0.32 & 3 & 1.0 \\
\hline C & 47 & 53 & 400 & 127 & 0.32 & 3 & 2.0 \\
\hline D & 47 & 53 & 400 & 127 & 0.32 & 3 & 3.0 \\
\hline $\mathrm{E}$ & 47 & 53 & 400 & 127 & 0.32 & 3 & 4.0 \\
\hline $\mathrm{F}$ & 47 & 53 & 400 & 127 & 0.32 & 3 & 5.0 \\
\hline
\end{tabular}

Table 4

Mixture composition of AAM pastes for porosity experiments.

\begin{tabular}{|c|c|c|c|c|c|c|}
\hline Mixture & $\mathrm{MB}(\mathrm{g})$ & Total liquid (ml) & L/B ratio & $\mathrm{NaOH}(\mathrm{M})$ & Admixture $(\mathrm{g} / \mathrm{kg})$ & Related concrete mixture design \\
\hline P0 & 1000 & 320 & 0.32 & 3 & 0.0 & A \\
\hline P1 & 1000 & 320 & 0.32 & 3 & 2.5 & B \\
\hline P3 & 1000 & 320 & 0.32 & 3 & 7.5 & $\mathrm{D}$ \\
\hline P5 & 1000 & 320 & 0.32 & 3 & 12.5 & $\mathrm{~F}$ \\
\hline
\end{tabular}

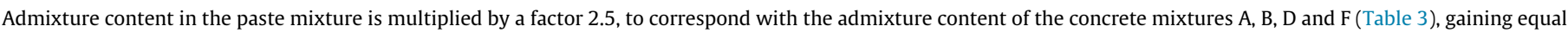
admixture dosage per $\mathrm{kg}$ of binder. 
The material electrical resistivity was tested at the ages of 28 and 91 days respectively on cubic samples $(150 \times 150 \times 150 \mathrm{~m}$ $\mathrm{m}^{3}$ ). The applied method was in accordance with the Two Electrodes Method (TEM) which is described in the reference [29].

The Rapid Chloride Migration (RCM) coefficient of concrete at the age of 28 and 91 days respectively was determined in accordance with the NT Build 492 . Samples $\left(150 \times 150 \times 150 \mathrm{~mm}^{3}\right)$ were stored until $24 \mathrm{~h}$ after casting in a $20^{\circ} \mathrm{C}$ water bath, securing maximal water saturation as normally AAM concrete is preferably not cured in a water bath. The experiments were performed on fourfold drilled samples ( $\varnothing 100 \mathrm{~mm}$ ).

The porosity measurements were performed with MIP on paste mixtures, measuring the pore sizes from 0.006 to $350 \mu \mathrm{m}$ (twofold measurement per sample). The sample preparation procedure was the following: at different ages of 7, 28 and 56 days samples were crushed and the reaction was stopped with liquid nitrogen and then the samples were vacuum freeze dried at $-28^{\circ} \mathrm{C}$, until constant mass to allow the pore solution to be removed by sublimation of ice microcrystals and maintaining the microstructure without significant damages. Mercury intrusion started at a low pressure of $0-0.003 \mathrm{MPa}$ followed by a pressure increase from 0.0036 to $210 \mathrm{MPa}$. The extrusion process started immediately afterwards, during which the pressure decreased from 210 to $0.14 \mathrm{MPa}$. The surface tension and the contact angle were fixed at $0.485 \mathrm{~N} / \mathrm{m}$ and 132 degrees, respectively.

\section{Results and discussions}

\subsection{Effect of admixture on the concrete characteristics}

\subsubsection{Effect of admixture on the fresh concrete workability}

Fig. 1 shows the fresh concrete slump over time as a function of the admixture content $\left(0-5 \mathrm{~kg} / \mathrm{m}^{3}\right)$ for concrete mixtures A-F, presented in Table 3 . The results clearly show a significantly affected slump behavior over time, from a very stiff consistency (concrete consistency class S0) without admixture, to a more fluid and then a highly fluid consistency at higher admixture contents. At a higher admixture content of more than $4-5 \mathrm{~kg} / \mathrm{m}^{3}$, deformation mechanisms (i.e. segregation and bleeding) of the fresh concrete mixtures were observed. For the tested mixtures, $3 \mathrm{~kg} / \mathrm{m}^{3}$ of admixture is identified as the optimum dosage, corresponding with $0.75 \mathrm{wt} \%$ of the binder content.

Further, the admixture was able to control the fresh concrete workability over time, showing a slowly declining slump (6-120 min). The slump modification by the admixture is also observed in the previous study [30], applying the same admixture in the pro-

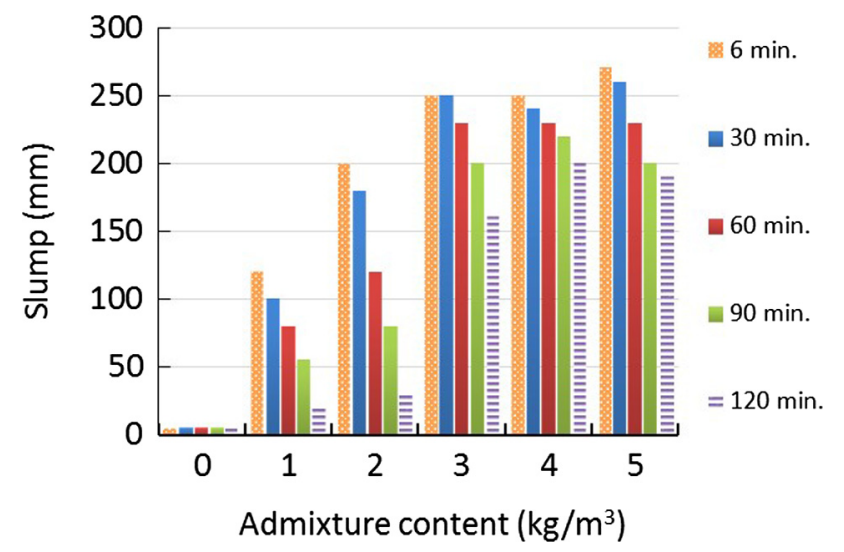

Fig. 1. Slump of fresh concrete mixtures A-F between 6 and 120 min versus admixture content.

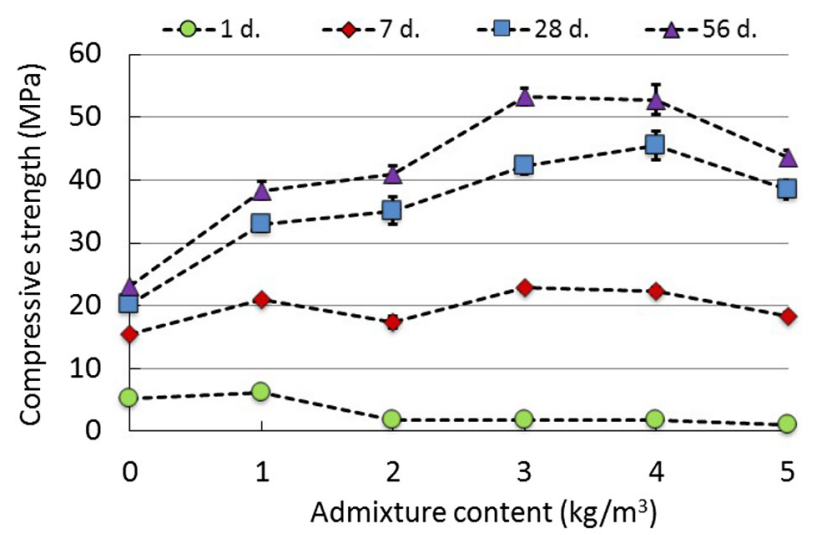

Fig. 2. Compressive strength development of concretes with varying admixture contents for mixtures A-F. Error bar: deviation of the strength based on 3 concrete samples.

duction of ultra-lightweight AAM concrete. However, using the admixture with a dosage of $\geq 3 \mathrm{~kg} / \mathrm{m}^{3}$, the retention of the slump between 6 and 120 min is clearly observed, implying an extended mixture setting time. This highly effective admixture-related result has been mainly observed in the literature for Portland cement systems $[11,12,31]$, as admixture use in AAM systems to modify the fresh mixture workability is much less effective [15,18,32]. This can be explained by the increasing admixture adsorption behavior, as a function of a higher admixture content, onto the positively charged mineral precursor particle surfaces [12,33,34]. This connection keeps the particles sterically at distance enhancing the mixture workability which results in a delay of the microstructure development indicated by a delayed mixture setting (Fig. 1) and consequently inhibited early age compressive strength progression (Fig. 2) [35,36].

\subsubsection{Effect of admixture on the compressive strength}

Fig. 2 shows the concrete compressive strength development as a function of the admixture content $\left(0-5 \mathrm{~kg} / \mathrm{m}^{3}\right)$, for mixtures A to $F$. The results indicate that a higher admixture content retards the early age ( 1 day) strength development. However, at the age of 7 days, all admixture containing concretes exhibit $\approx 20 \mathrm{MPa}$ (varying between 18 and $23 \mathrm{MPa}$ ), which is higher than the non-admixture reference of $15 \mathrm{MPa}$. Over time, this effect is even more significant, as the strengths increase more (42-46 MPa at 28 days) in comparison with the reference concrete (20 MPa at 28 days). It should be noted that the lower strength development from the reference concrete (containing no admixture) is attributed to the compaction influence due to its relatively stiff fresh mixture consistency (Fig. 1). As no significant differences of the visible surface smoothness and measured fresh concrete material density between all tested samples is observed.

The optimal admixture content with regard to compressive strength is about $3-4 \mathrm{~kg} / \mathrm{m}^{3}$. The decline in strength with the admixture content of $\approx 5 \mathrm{~kg} / \mathrm{m}^{3}$ could be explained by the observed mixture segregation, while unstable and inhomogeneous mixtures can result in a higher concrete porosity and therefore lower strengths. This will be further discussed in Section 3.2.4. The use of admixtures, within an optimal range, improves the mixture workability and particle packing and therefore the concrete densification which consequently leads to an enhanced material strength [37]. However, apart from this, other fundamental physical and chemical admixture-related mechanisms could also be of influence: 


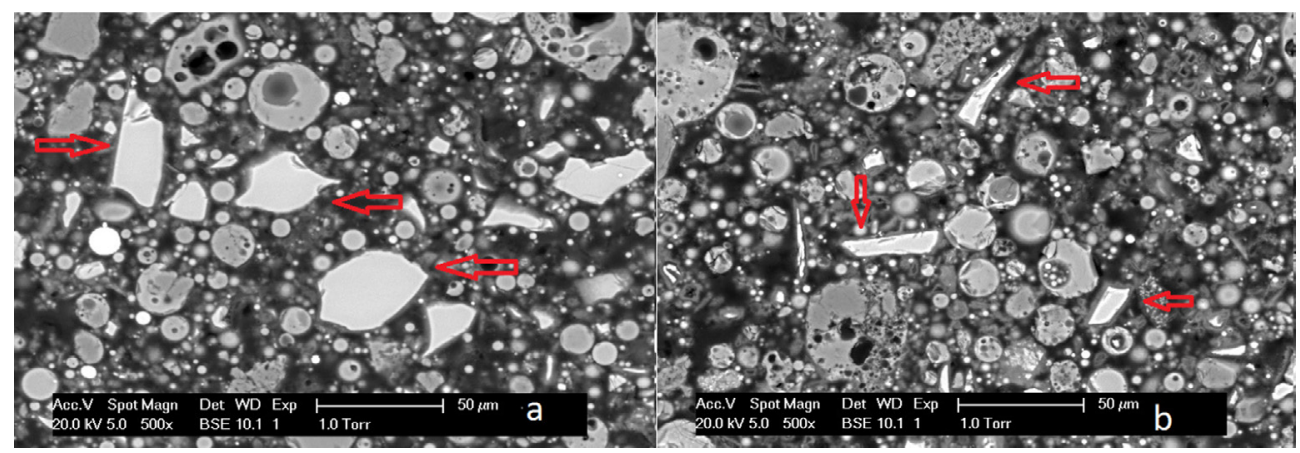

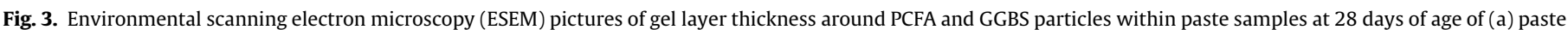

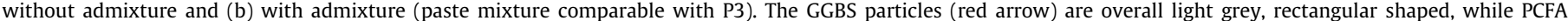

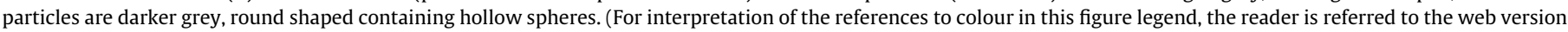
of this article.)

- For the early age strength (1-7 days): It is known from the literature that a higher (polycarboxylate) admixture content increases and partially controls the precursor element release (mainly calcium) by slowing down the mineral precursor dissolution processes of mainly GGBS [38]. This is initiated by admixture adsorption, due to calcium bridging onto mineral surfaces and element complexation of the admixture (ligand formation) that disrupt nucleation and early age polycondensation. Further, the observed 1 day strength retardation is in line with the prolonged setting time of the fresh concrete, which is increasingly noticeable at higher admixture contents (Fig. 1).

- For the later age strength (7-56 days): It was observed in previous research [39] that the reaction product (gel layer thickness) around GGBS particles within a 28 hardening period, is significantly thicker with admixture compared to a non-admixture reference paste mixture, as shown in Fig. 3a and b. This effect has been reported in the literature, on both AAM [14] and Portland cement [26] systems with the enhanced matrix development, by densifying the interfacial transition zone (ITZ) between: (I) the newly formed gel matrix and solid-binder and (II) the newly formed gel matrix and the aggregate particles [26], which can lead towards a modified material strength performance (Fig. 2). This will be further discussed in Sections 3.2.3 and 3.2.4.

\subsubsection{Effect of admixture on the Cl-migration}

The previous sections demonstrated that the admixture content strongly influences the fresh and hardened state AAM concrete performance over time. Fig. $4 a$ and $b$ show the effect of the admixture content $\left(0-5 \mathrm{~kg} / \mathrm{m}^{3}\right)$ on the Cl-migration coefficient (abbreviation is Drcm) of concrete mixtures A to $\mathrm{F}$, at the age of 28 and 91 days, respectively. At the age of 28 days, the $\mathrm{Cl}-$ migration rate in concrete is strongly influenced by the admixture content, as shown in Fig. 4a. Samples containing 0-2 to about $3 \mathrm{~kg} / \mathrm{m}^{3}$ admixture have a comparable and low (approximately $3 \times 10^{-12} \mathrm{~m}^{2} / \mathrm{s}$ ) Cl-migration, even though, the initial fresh mixture slump increases significantly as an effect of a higher admixture dosage (Fig. 1). Additionally, this indicates that the references sample (containing no admixture) possess a high compaction level and related matrix density even though its relative stiff fresh mixture consistency.

The overall performance (mixtures containing $0-2$ to about 3 $\mathrm{kg} / \mathrm{m}^{3}$ admixture) is in line with the literature [9], stating that AAM and specifically fly ash-dominated systems can obtain a low Cl-diffusion rate. On the contrary, at a high admixture content of $\geq 3-5 \mathrm{~kg} / \mathrm{m}^{3}$, the Cl-migration coefficient strongly increases at which these three $D_{\mathrm{rcm}}$ values are followed by a perfect exponential trend (R: 1.00). This increase, is probably related to a higher porosity or abundance of capillary pores caused by the segregation, consequently higher permeability of the concrete that strongly influences the Cl-migration [9]. This effect can also be compared with a higher liquid content or higher L/B ratio, which also significantly increases the porosity [40]. The AAM porosity properties are further discussed in Section 3.2.3, in addition further study is needed to gain more understanding of the observed results. For the 91 days results (Fig. 4b), all concrete mixtures (non- to high admixture contents) show a decrease in Cl-migration, towards a comparable and low level of about $2.6 \times 10^{-12} \mathrm{~m}^{2} / \mathrm{s}$. Surprisingly,
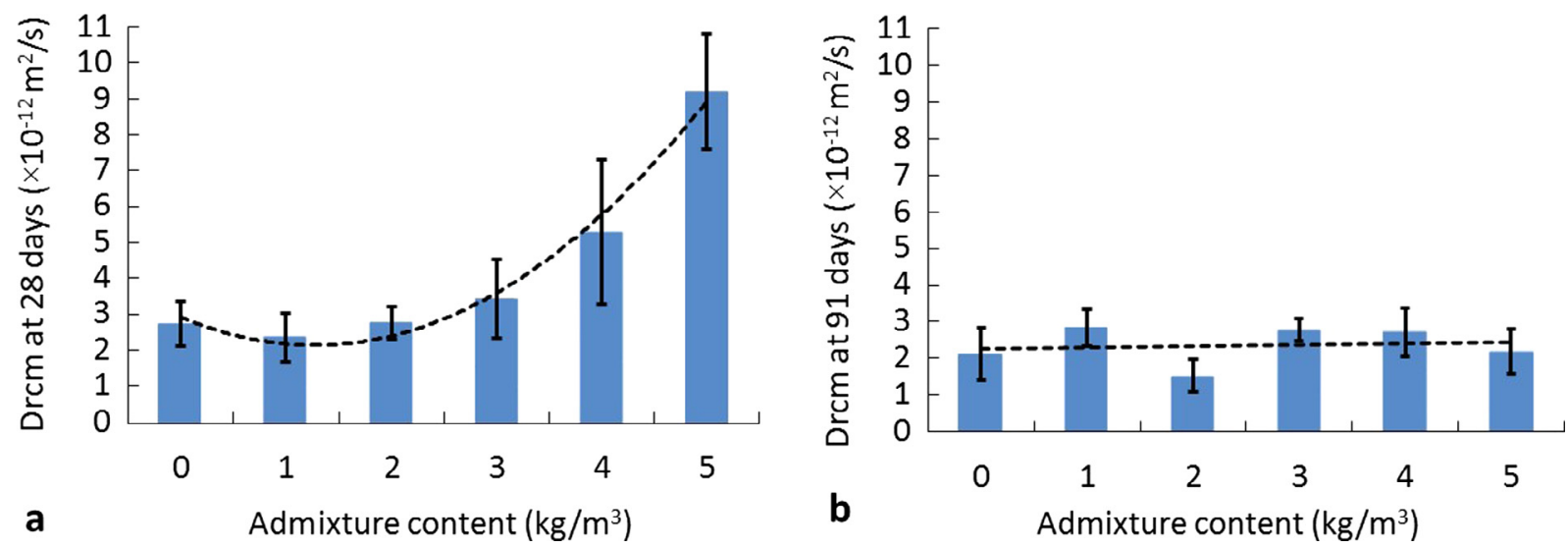

Fig. 4. Chloride migration coefficient of (a) 28 and (b) 91 days old AAM concretes with varying admixture contents for mixtures A-F. The dashed line is the trend line. 


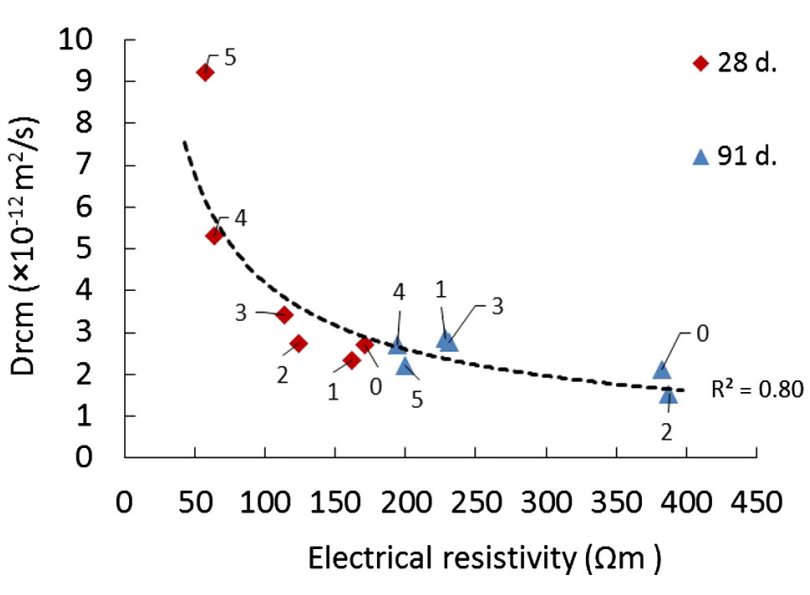

Fig. 5. The relation between $\mathrm{Cl}$-migration rate (Drcm) and material electrical resistivity of AAM concretes at 28 and 91 days for mixtures A-F. The numbers close to data points are the admixture content $(\mathrm{g} / \mathrm{kg})$. All samples' $\mathrm{pH}$ range between 12.0 and 12.5 .

mixtures with an admixture content $\geq 3 \mathrm{~kg} / \mathrm{m}^{3}$ show the most significant $\mathrm{Cl}$ migration coefficient decline. This effect can be assumed to be controlled by the element dissolution behavior of PCFA in the binder, favoring a further densification of the matrix $[9,41]$ and consequently improved strength (Fig. 2), resulting in a reduced diffusion rate. This effect is also observed in the literature [42-45], showing that the matrix of AAM and Portland cement-based mixture, containing PCFA, significantly densifies in the period of 2891 days after casting. Additionally, material electrical resistivity served in this study as a quick and reliable indicator to determine the concrete permeability and related $\mathrm{Cl}$-migration performance [29]. Fig. 5 shows the Cl-migration coefficient in relation with the material electrical resistivity of 28 and 91 days old AAM concrete mixtures A to $\mathrm{F}$.

The results show a significant resistivity increase at an increasing concrete age from 28 to 91 days, as well as a decreased Drcm over time. This behavior is comparable with Blast furnace slag cement mixtures [29], although overall the AAM concrete mixtures exhibit far lower resistivity values. in comparison, at 28 days the Portland cement mixtures show RCM values ranging between about $1-5 \times 10^{-12} \mathrm{~m}^{2} / \mathrm{s}$ with an electrical resistivity ranging between $175-500 \Omega \mathrm{m}$ [29], where the representative AAM value range between about $2-5 \times 10^{-12} \mathrm{~m}^{2} / \mathrm{s}$ with a resistivity ranging between 60 and $175 \Omega \mathrm{m}$. This difference in resistivity between both systems is maintained when the age of the concrete increases. Further, the electrical resistivity of both systems strongly increase, which is an indication of further material densification and consequently lower permeability. The $\mathrm{Cl}$-migration and electrical resistivity results also indicate that the effect of the admixture content is related to the porosity development of paste and accordingly of concrete samples (further discussed in Section 3.3).

\subsection{Effect of admixture on the paste characteristics}

\subsubsection{Effect of admixture on the fresh paste flowability}

The paste slump was measured directly after mixing and showed a similar behavior (flowability modifying effect) as observed in the concrete mixtures (Fig. 1). An increase of paste flowability as a function of admixture content: 0/1/3/5 g/ kg admixture resulted in a slump of $200 / 230 / 240 / 250 \mathrm{~mm}$, respectively (obtained data points follow a logarithmic trend (R: 0.95)).

\subsubsection{Effect of admixture on the compressive strength}

Fig. 6 plots the compressive strength development of paste as a function of the admixture content $(0-5 \mathrm{~g} / \mathrm{kg}$ binder $)$ for mixtures

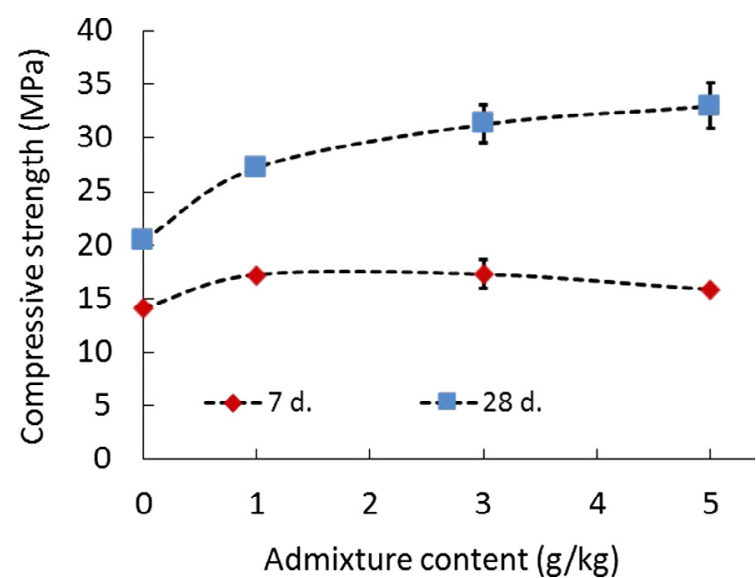

Fig. 6. Compressive strength development of AAM paste mixtures P0-P5 versus admixture content

P0 to P5, which are described in Table 4. A higher admixture content slightly retards the early age strength development. While at 28 days, the strength is increased when increasing the admixture content. The admixture-related strength development shows strong similarities with that of the tested concrete mixtures, as described in Section 3.1.2. Additionally, the paste slump, measured directly after mixing, shows a similar behavior (flowability modifying effect) observed for the concrete mixtures due to the increase of the flowability at an increased admixture dosage. It should be noted that difference in strength increase in paste and concrete is obverved, which might be attributed to several reasons, including aggregate type and content, workability, compaction effort and particle packing.

\subsubsection{Effect of admixture on the porosity}

Figs. 7-9 show the development of the AAM paste porosity (756 days) of medium to large pore size $(0.01-100 \mu \mathrm{m})$, as a function of the admixture content ( $0-5 \mathrm{~g} / \mathrm{kg}$ binder) for mixtures P0 to P5. It is shown in Fig. 7 that after 7 days AAM pastes with 0 and $1 \mathrm{~g} / \mathrm{kg}$ admixture have a similar size pore distribution. However, at high admixture contents $(3-5 \mathrm{~g} / \mathrm{kg})$, larger pores are observed in the paste mixtures, which is shown (Fig. 7b) by an extreme growth (hump) for $1-2 \mu \mathrm{m}$ pores. At the ages of 28-56 days, this hump completely disappears for all samples, only pores with smaller size or a refined porosity are observed, as shown in Figs. 8 and 9. The results also show a more refined paste pore structure as a function of the increasing admixture content.

Two distinct pore types are identified as being critical with regard to material strength and liquid and ion transport for paste or concrete: (1) effective capillary pores that vary between 0.01 and $10 \mu \mathrm{m}(10-10.000 \mathrm{~nm})$ and (2) gel pores with a size $<0.01$ $\mu \mathrm{m}(<10 \mathrm{~nm})[46,47]$. Fig. 10a and b show the total and effective capillary porosity development (7-56 days) of AAM pastes, as a function of the admixture content $(0-5 \mathrm{~g} / \mathrm{kg}$ binder) for mixtures P0 to P5.

With regard to the total porosity (Fig. 10a), all samples show similar values after 7 days of curing. However, over time after 28 and 56 days, the total porosity is significantly decreased at an increasing admixture content, following a logarithmic trend. The measured porosity of the non-admixture containing reference mixture (P0) is in line with the literature [7]. A different behavior is observed for the effective capillary porosity (Fig. 10b). At 7 days, an increase in effective capillary porosity is related to a higher admixture content (followed by a linear trend). However, further over time at 28-56 days, this effect is altered, where a lower effective capillary porosity is obtained at an increasing admixture con- 

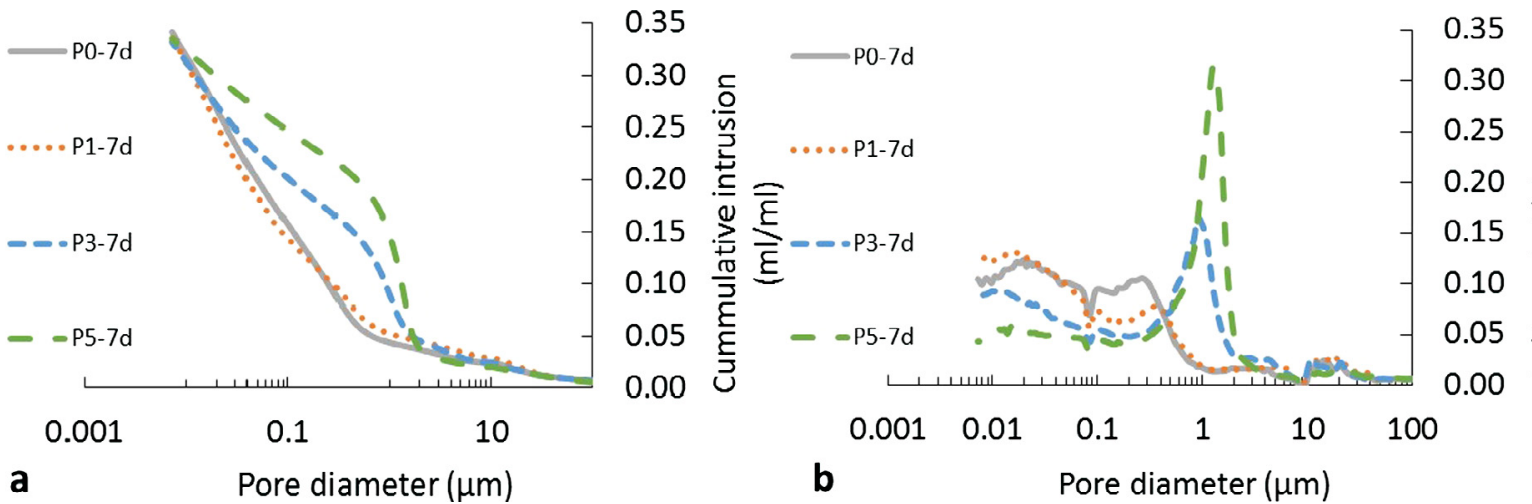

0.35

0.30

0.25

0.20

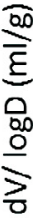

Fig. 7. Pore size distribution at 7 days of age of AAM paste for mixtures P0-P5, with a varying admixture content: (a) pore size distribution; (b) pore size distribution differential curve.
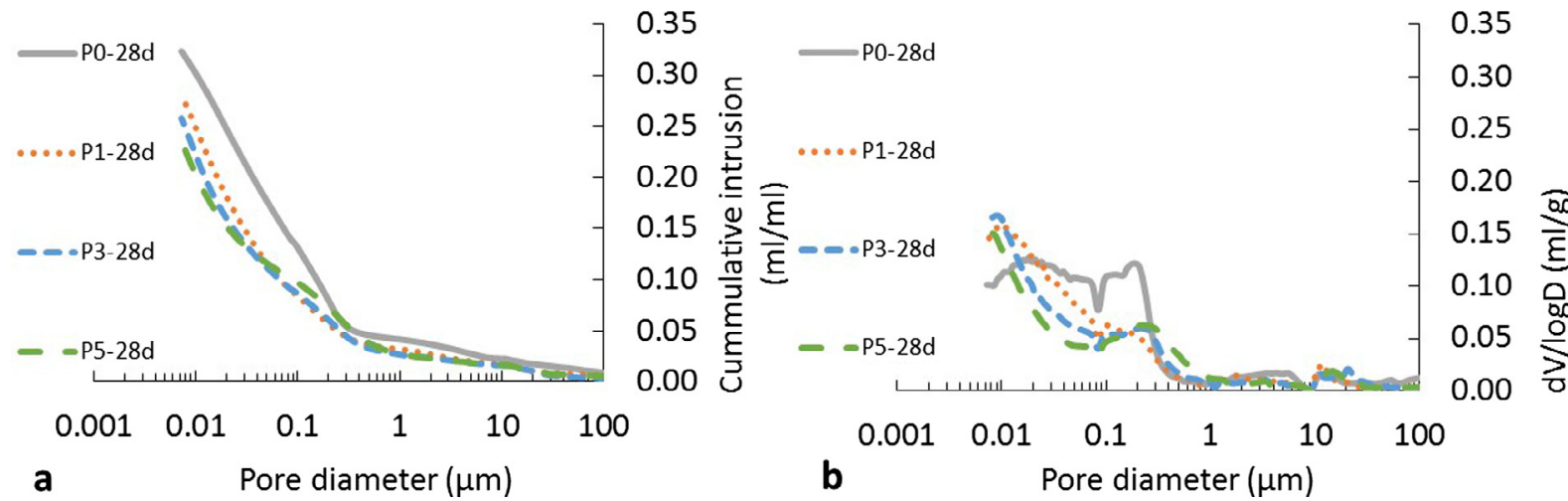

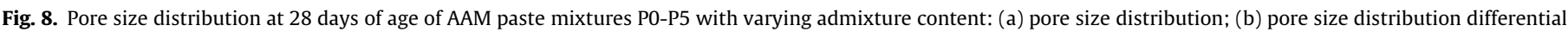
curve.
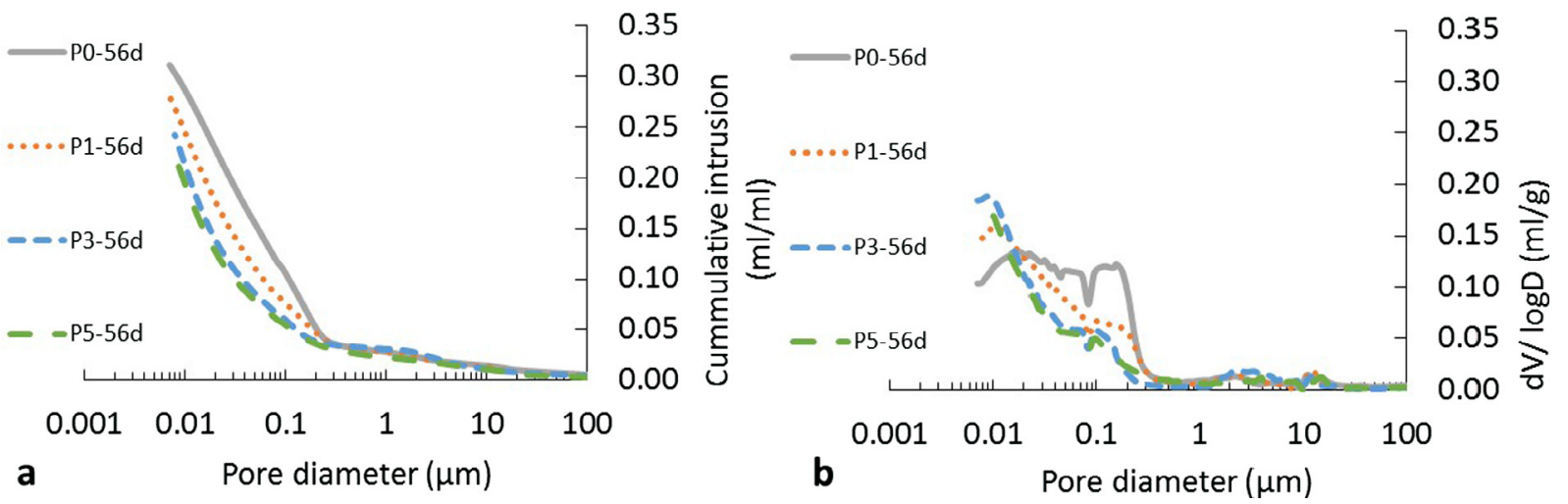

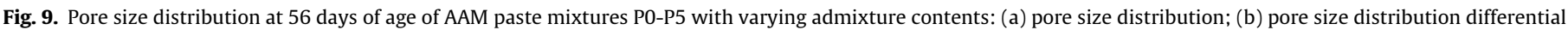
curve.

tent (followed by a logarithmic trend). This admixture effect of pore structure refinement in AAM has never been reported in the literature. Often a reduced porosity over time in AAM is observed, when a higher GGBS binder content instead of PCFA and or alkaline activator (silicate source) is used [41]. In addition, Fig. 11 shows the relation between the total porosity and the effective capillary porosity dependent on the admixture content over time for AAM pastes (original data of Fig. 10a, b). The results show a strong decrease of the total porosity at a decreasing effective capillary porosity over time with a higher admixture content, following a logarithmic trend.

\subsubsection{Porosity versus strength progression}

Fig. 12 shows the relation and prediction (trend) between the total and effective capillary paste porosities and the paste compressive strength over time. Firstly, a higher admixture content results in a lower total and effective capillary porosity over time at the age of 28 days and therefore increases the material strength. Secondly, the relation between strength and porosity of cementbased (porous) materials such as AAM can be predicted by using a (non)-linear trend. As a linear trend sometimes overestimates the results and the literature [48] indicates that both porosity parameters follow a different trend to explain the strength. For 

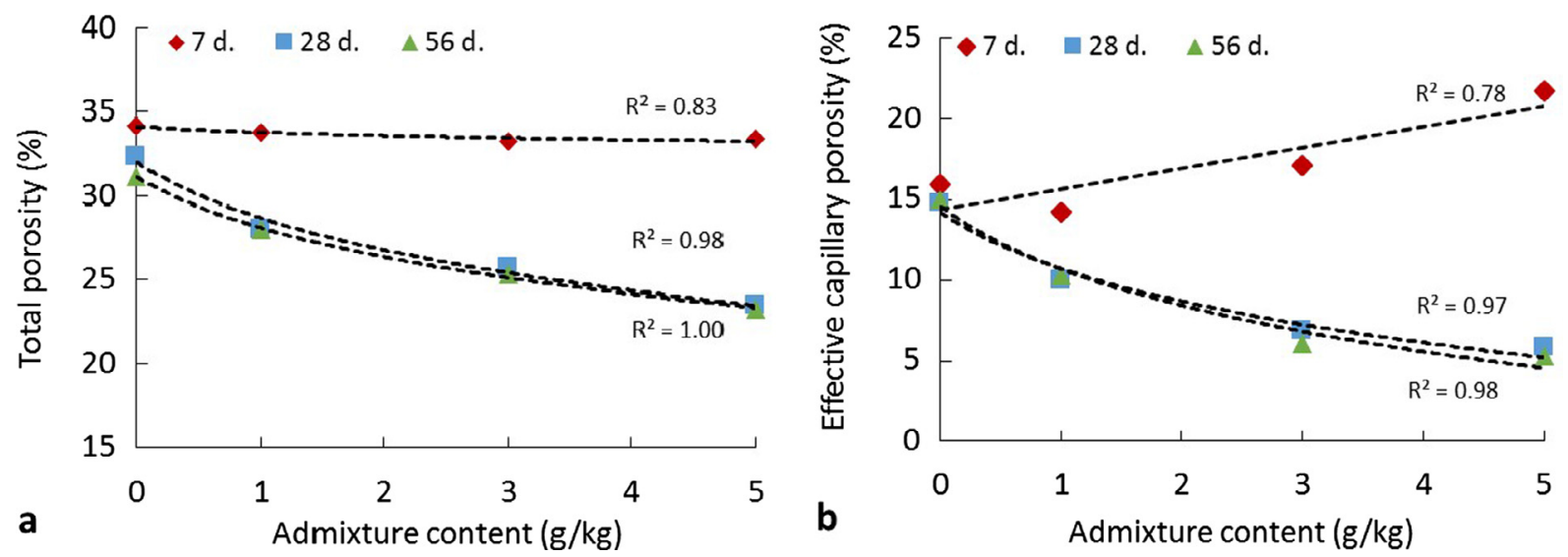

Fig. 10. Porosity development at 7/28/56 days of age of AAM paste mixtures P0-P5 with varying admixture contents: (a) Total porosity; (b) Effective capillary porosity.

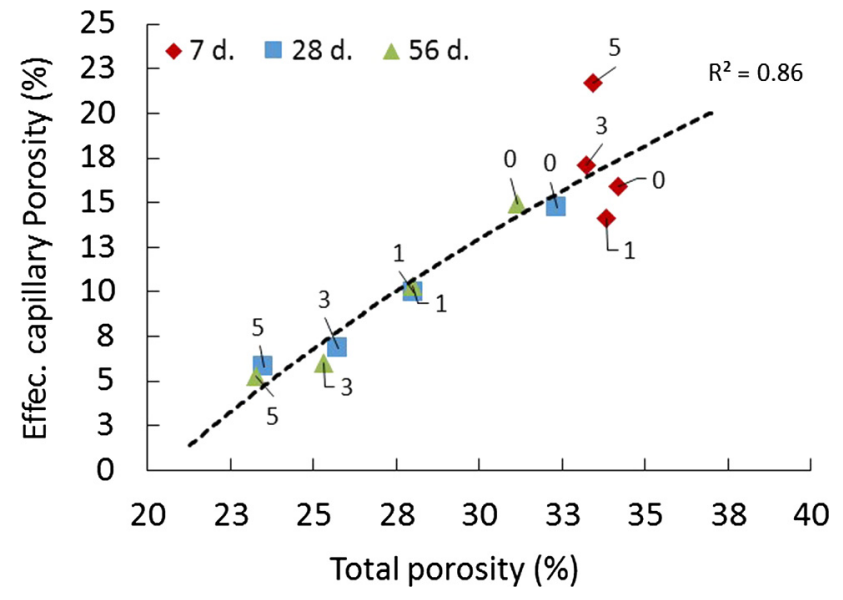

Fig. 11. Correlation between total and effective capillary porosity at 7, 28 and 56 days of age for AAM paste for mixtures P0-P5. Values close to the data points are the admixture content $(\mathrm{g} / \mathrm{kg})$.

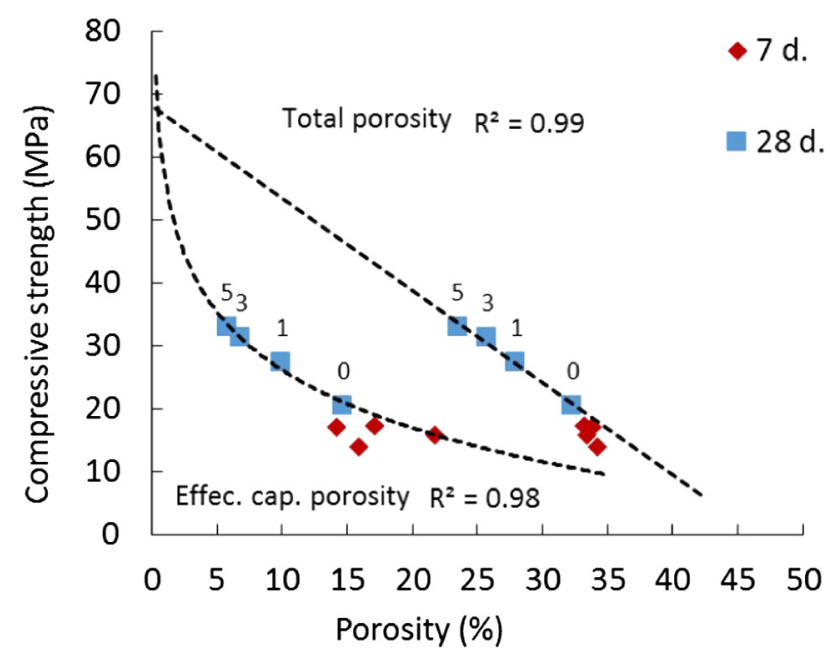

Fig. 12. Correlations between: paste compressive strength and the total and effective capillary paste porosities over time (7-28 days age) for mixtures P0-P5. Values close the 28 days data points are the admixture contents $(\mathrm{g} / \mathrm{kg})$. Fitted lines are based on data point at 28 days of age.

the total porosity, a linear trend is used and for the effective capillary porosity a logarithmic trend is derived. Both findings are in line with the literature on Portland cement mortars [48].

\subsection{AAM concrete discussions}

The results presented in the previous sections on paste and concrete mixtures show that the use of a plasticizing admixture enhances the flowability properties and the hardened state performance of AAM. Fig. 13 shows the relation between the $\mathrm{Cl}$ migration coefficient (Drcm) at 28 days of AAM concretes and the total and effective capillary porosity of AAM pastes at 28 days. From this correlation it can be concluded that AAM concretes with a low to optimal admixture content $\left(1-3 \mathrm{~kg} / \mathrm{m}^{3}\right)$ possess a low $\mathrm{Cl}$ migration rate and related material electrical resistivity as shown in Fig. 5, indicating a low permeability. This is in line with the significant pore structure refinement over time as shown in Figs. 7-9. This refinement is significantly enhanced by admixture with a proper dosage, as the ingress of $\mathrm{Cl}$-ions is largely controlled by the concrete permeability which is influenced by the porosity while excessive admixture amount leads to segregation and higher porosity $[41,43,44]$. Furthermore, this AAM matrix densification effect by using admixture is supported by the literature on Port-

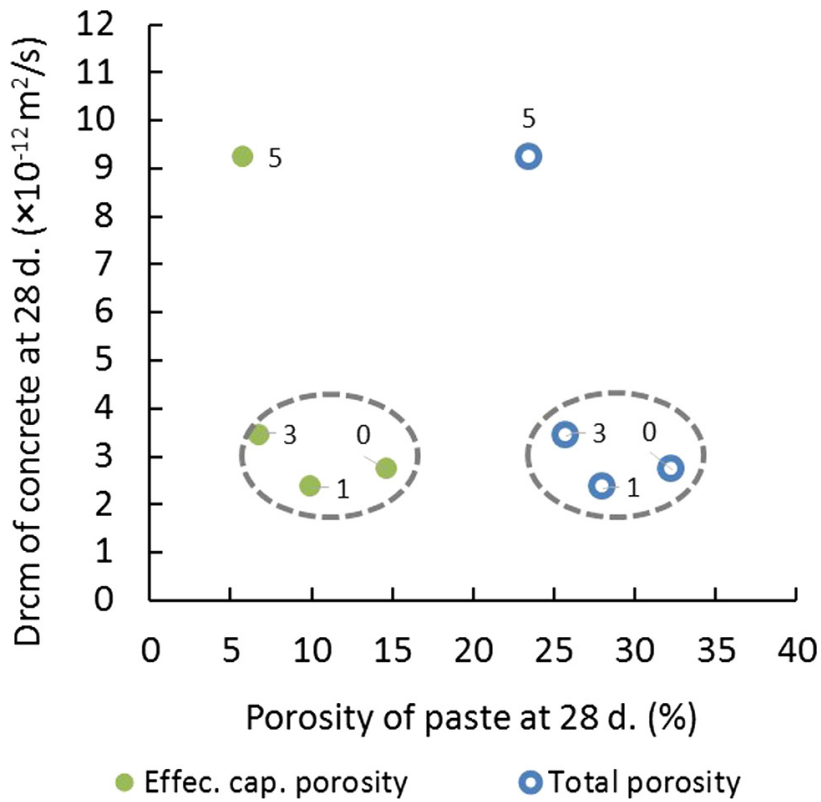

Fig. 13. Chloride migration of 28 days old $A A M$ concretes (mixtures $A / B / D / F$ of Table 3 ) in relation to the total and effective capillary porosity of 28 days old AAM pastes (mixtures P0-P5). Values close to the data points are the admixture contents $\left(\mathrm{g} / \mathrm{kg}\right.$ in paste and $\mathrm{kg} / \mathrm{m}^{3}$ in concrete). 
land cement mixtures [37], and this effect is observed and detailed analyzed in the previous study [39] of AAM paste mixtures, as shown in Fig. 3. Where scanning electron microscopy (SEM) analysis showed that the matrix of a AAM paste, at 28 days age (containing about $3 \mathrm{~kg} / \mathrm{m}^{3}$ of admixture, which is found to be the optimal content in the present study), has a significantly thicker $(\approx 34 \%)$ newly formed gel layer around the GGBS particles compared to the non-admixture reference samples. This leads to a more densified and lower permeable AAM matrix with a significantly higher compressive strength (supported by Fig. 2), which is strongly related to a lower total porosity as supported by Fig. 12 .

The plotted data in Fig. 13 show that both the total and effective paste porosity within a defined range have comparable influences on the Cl-migration in concrete. No distinct trend can be observed between both porosity parameters and their individual influences on Cl-migration, which can be explained by the fact that both parameters at 28 days age are strongly related with each other (Fig. 11). However, data obtained from a preliminary study [49] on a 28-day old admixture-modified AAM concrete (mixture comparable with AAM mixture D using $3 \mathrm{~kg} / \mathrm{m}^{3}$ of admixture), show a relatively high abundance of connected spherical voids in the matrix. This is supported by the literature [43,47], reporting that the matrix permeability of PCFA-dominated AAM and Portland cement pastes is strongly related with the effective capillary porosity. Since the connected pores provide a continuous channel for transport, they largely affect the permeability and the ion ingress in the matrix $[43,44]$. It should be noted that the porosities shown in Fig. 13 were acquired from paste sample while the $\mathrm{Cl}$-migration results were based on concrete samples. As mentioned in Section 3.1.1, a higher admixture dosage than $3 \mathrm{~kg} / \mathrm{m}^{3}$ results in concrete segregation that leads to a clearly increased $\mathrm{Cl}$-migration (mix 5 in Fig. 13). Nevertheless, it can be concluded that both total porosity and effective capillary porosity can be used to indicate the Cl-migration property in AAM.

\section{Conclusions}

The effects of a polycarboxylate admixture on the flowability properties and hardened state performance of AAM concrete and paste mixtures are investigated. The relations between the alteration of the pore structure and related material strength and chloride ingress that changed, dependent on the admixture content, are evaluated. Based on the obtained results, the following conclusions can be drawn:

- The workability of the fresh AAM concrete significantly improves from a zero slump towards a maximal measurable slump value $(>250 \mathrm{~mm}$ ) with a relatively low admixture content $(0.25-0.75 \mathrm{wt} \%$ of the binder). It is likely that the setting time of the concrete mixture is increasingly prolonged with a higher admixture content, even up to $120 \mathrm{~min}$ at an admixture content of about $3 \mathrm{~kg} / \mathrm{m}^{3}$.

- The concrete compressive strength increases significantly over time at higher admixture contents. The 7 and 28 days compressive strengths of admixture-containing concrete (at an optimal admixture content $\left(3-4 \mathrm{~kg} / \mathrm{m}^{3}\right)$ ) are about 22 and $44 \mathrm{MPa}$, respectively, while that of the reference concrete are only 15 and $23 \mathrm{MPa}$, respectively.

- The pore structure of the AAM paste mixtures is strongly refined over time at an increasing admixture content, resulting in a significant decrease of the total and effective capillary porosity and reduced material permeability. A significant relation is found between the compressive strength and the porosity.

- The chloride migration coefficients of admixture-modified AAM concrete at the ages of 28 and 91 days, at an optimal admixture content, are about $3.0 \times 10^{-12} \mathrm{~m}^{2} / \mathrm{s}$ and $2.6 \times 10^{-12} \mathrm{~m}^{2} / \mathrm{s}$, respectively. A relation between the $\mathrm{Cl}$-migration coefficient $($ Drcm) and material electrical resistivity $(\Omega \mathrm{m})$ over time is derived for the AAM concrete mixtures.

\section{Acknowledgements}

The authors thank their research sponsors Van Gansewinkel Minerals, Cementbouw Mineralen and SQAPE Technology, all from the Netherlands. We wish to express our gratitude to Mr. D. Duprie and Mr. G. van der Berg and Dr. P.I.J. Kakebeeke, all from Cementbouw, for their laboratory support and expert advice on the concrete production.

\section{References}

[1] K. Arbi, M. Nedeljković, Y. Zuo, G. Ye, A review on the durability of alkaliactivated fly ash/slag systems: advances, issues, and perspectives, Ind. Eng. Chem. Res. (2016), https://doi.org/10.1021/acs.iecr.6b00559.

[2] J.L. Provis, S.A. Bernal, Geopolymers and related alkali-activated materials, Annu. Rev. Mater. Res. 44 (2014) 299-327.

[3] Handbook of Alkali-activated cement, mortars and concretes. (Woodhead Publishing, 2015).

[4] Alkali Activated Materials, state of the art report, RILEM TC 224-AAM. 13, (Springer, 2014).

[5] P.S. Deb, P. Nath, P.K. Sarker, The effects of ground granulated blast-furnace slag blending with fly ash and activator content on the workability and strength properties of geopolymer concrete cured at ambient temperature, Mater. Des. 62 (2014) 32-39.

[6] I. Ismail et al., Modification of phase evolution in alkali-activated blast furnace slag by the incorporation of fly ash, Cem. Concr. Compos. 45 (2014) 125-135.

[7] N.K. Lee, J.G. Jang, H.K. Lee, Shrinkage characteristics of alkali-activated fly ash/ slag paste and mortar at early ages, Cem. Concr. Compos. 53 (2014) 239-248.

[8] X. Gao, Q.L. Yu, H.J.H. Brouwers, Reaction kinetics, gel character and strength of ambient temperature cured alkali activated slag-fly ash blends, Constr. Build. Mater. 80 (2015) 105-115.

[9] I. Ismail et al., Influence of fly ash on the water and chloride permeability of alkali-activated slag mortars and concretes, Constr. Build. Mater. 48 (2013) $1187-1201$

[10] H. Huang et al., Improvement on microstructure of concrete by polycarboxylate superplasticizer (PCE) and its influence on durability of concrete, Constr. Build. Mater. 110 (2016) 293-299.

[11] Science Technology of concrete admixtures. (Woodhead Publishing, 2016)

[12] R.J. Flatt, Superplasticizers and the rheology of concrete. in: N. Roussel (Ed.), Understanding the rheology of concrete, 144-201 (Woodhead Publishing, 2012).

[13] B. Nematollahi, J. Sanjayan, Effect of different superplasticizers and activator combinations on workability and strength of fly ash based geopolymer, Mater. Des. 57 (2014) 667-672.

[14] S. Demie, M.F. Nuruddin, N. Shafiq, Effects of micro-structure characteristics of interfacial transition zone on the compressive strength of self-compacting geopolymer concrete, Constr. Build. Mater. 41 (2013) 91-98.

[15] A.M. Rashad, A comprehensive overview about the influence of different admixtures and additives on the properties of alkali-activated fly ash, Mater. Des. 53 (2014) 1005-1025.

[16] K. Arbi et al., Experimental study on workability of alkali activated fly ash and slag-based geopolymer concretes, in: Geopolymers: The Route to Eliminate Waste and Emissions in Ceramic and Cement Manufacturing. ISBN: 9781326377328 75-78 (ECI, 2015).

[17] A.A. Aliabdo, A.E.M. Abd Elmoaty, H.A. Salem, Effect of water addition, plasticizer and alkaline solution constitution on fly ash based geopolymer concrete performance, Constr. Build. Mater. 121 (2016) 694-703.

[18] J.G. Jang, N.K. Lee, H.K. Lee, Fresh and hardened properties of alkali-activated fly ash/slag pastes with superplasticizers, Constr. Build. Mater. 50 (2014) 169176.

[19] A.M. Rashad, Alkali-activated metakaolin: a short guide for civil engineer - an overview, Constr. Build. Mater. 41 (2013) 751-765.

[20] A.M. Rashad, A comprehensive overview about the influence of different additives on the properties of alkali-activated slag - a guide for Civil Engineer, Constr. Build. Mater. 47 (2013) 29-55.

[21] M. Al-Majidi, A. Lampropoulos, A. Cundy, Effect of alkaline activator, water, superplasticiser and slag contents on the compressive strength and workability of slag-fly ash based geopolymer mortar cured under ambient temperature, Int. J. Civ. Environ. Architectural Eng. 10 (2016) 285-289.

[22] F. Puertas, M. Palacios, J.L. Provis, Admixtures, in: J.L. Provis, J.S.J. van Deventer (Eds.), Alkali Activated Materials, State-of-the-art Report, RILEM TC 224-AAM, 145-156 (Springer, 2014).

[23] B. Nematollahi, J. Sanjayan, Efficacy of available superplasticizers on geopolymers, Res. J. Appl. Sci. Eng. Technol. 7 (2014) 1464-1468. 
[24] C. Bilim, O. Karahan, C.D. Atiş, S. Ilkentapar, Influence of admixtures on the properties of alkali-activated slag mortars subjected to different curing conditions, Mater. Des. 44 (2013) 540-547.

[25] M. Palacios, Y.F. Houst, P. Bowen, F. Puertas, Adsorption of superplasticizer admixtures on alkali-activated slag pastes, Cem. Concr. Res. 39 (2009) 670 677.

[26] J. Hu, Porosity of Concrete - Morphological Study of Model Concrete, Delft University of Technology, 2004

[27] K. Komnitsas, D. Zaharaki, Utilisation of low-calcium slags to improve the strength and durability of geopolymers, in: J.L. Provis, J.S.J. Van Deventer (Eds.), Geopolymers. Structure, Processing, Properties and Industrial Applications, 343-375, Woodhead Publications, 2009.

[28] M. Hunger, H.J.H. Brouwers, Flow analysis of water-powder mixtures: application to specific surface area and shape factor, Cem. Concr. Compos. 31 (2009) 39-59.

[29] R. Van Noort, M. Hunger, P. Spiesz, Long-term chloride migration coefficient in slag cement-based concrete and resistivity as an alternative test method, Constr. Build. Mater. 115 (2016) 746-759.

[30] D.M.A. Huiskes, A. Keulen, Q.L. Yu, H.J.H. Brouwers, Design and performance evaluation of ultra-lightweight geopolymer concrete, Mater. Des. 89 (2015) 516-526.

[31] Y.F. Houst et al., Design and function of novel superplasticizers for more durable high performance concrete (superplast project), Cem. Concr. Res. 38 (2008) 1197-1209.

[32] A.M. Rashad, Y. Bai, P.A.M. Basheer, N.B. Milestone, N.C. Collier, Hydration and properties of sodium sulfate activated slag, Cem. Concr. Compos. 37 (2013) 20-29.

[33] L. Ferrari, J. Kaufmann, F. Winnefeld, J. Plank, Interaction of cement model systems with superplasticizers investigated by atomic force microscopy, zeta potential, and adsorption measurements, J. Colloid Interface Sci. 347 (2010) $15-24$.

[34] A. Habbaba, J. Plank, Interaction between polycarboxylate superplasticizers and amorphous ground granulated blast furnace slag, J. Am. Ceram. Soc. 2863 (2010) 2857-2863.

[35] G. Gelardi, R.J. Flatt, Working mechanisms of water reducers and superplasticizers, in: P.-C. Aïtcin, R.J. Flatt (Eds.), Science and Technology of Concrete Admixtures, 527-275, Woodhead Publishing, 2016.
[36] D. Marchon, R.J. Flatt, Impact of chemical admixtures on cement hydration, in: P.-C. Aïtcin, R.J. Flatt (Eds.), Science and Technology of Concrete Admixtures, 279-299, Woodhead Publishing, 2016.

[37] M. Toledano-Prados, M. Lorenzo-Pesqueira, B. González-Fonteboa, S. SearaPaz, Effect of polycarboxylate superplasticizers on large amounts of fly ash cements, Constr. Build. Mater. 48 (2013) 628-635.

[38] P. Suraneni, M. Palacios, R.J. Flatt, New insights into the hydration of slag in alkaline media using a micro-reactor approach, Cem. Concr. Res. 79 (2015) 209-2016.

[39] S. Zhang, Analytical elements identification of geopolymer paste on network structure influenced by different specific geopolymer admixtures, Delft University of Technology, 2014.

[40] X. Chen, S. Wu, Influence of water-to-cement ratio and curing period on pore structure of cement mortar, Constr. Build. Mater. 38 (2013) 804-812.

[41] Z. Zhang, H. Wang, Analysing the relation between pore structure and permeability of alkali-activated concrete binders, in: F. Pacheco-Torgal, J.A. Labrincha, C. Leonelli, A. Palomo, P. Chindaprasirt (Eds.), Handbook of Alkali Activated Cements, Mortars and Concretes, 235-262, Woodhead Publications, 2015.

[42] R. Siddique, M.I. Khan, Fly ash, Supplementary Cementing Materials, Springer, 2011, pp. 1-61.

[43] Z. Yu, Microstructure Development and Transport Properties of Portland Cement-fly Ash Binary Systems, Technical University Delft, 2015.

[44] Y. Ma, J. Hu, G. Ye, The pore structure and permeability of alkali activated fly ash, Fuel 104 (2013) 771-780.

[45] J. Liu, X. Wang, Q. Qiu, G. Ou, F. Xing, Understanding the effect of curing age on the chloride resistance of fly ash blended concrete by rapid chloride migration test, Mater. Chem. Phys. 196 (2017) 315-323.

[46] R.A. Cook, K.C. Hover, Mercury porosimetry of hardened cement pastes, Cem. Concr. Res. 29 (1999) 933-943.

[47] Y. Ma, Microstructure and Engineering Properties of Alkali Activated Fly Ash as an environment friendly alternative to Portland cement, Delft Technical University of Technology, 2013.

[48] X. Chen, S. Wu, J. Zhou, Influence of porosity on compressive and tensile strength of cement mortar, Constr. Build. Mater. 40 (2013) 869-874.

[49] S. Valcke, Durability and Microstructure, Alkali activated concrete, 2012. 